\title{
Simple and Objective Prediction of Survival in Patients with Lung Cancer: Staging the Host Systemic Inflammatory Response
}

\author{
Derek Grose, ${ }_{1}^{1}$ Graham Devereux, ${ }^{2}$ Louise Brown, ${ }^{1}$ Richard Jones, ${ }^{1}$ Dave Sharma, ${ }^{3}$ \\ Colin Selby, ${ }^{4}$ David S. Morrison, ${ }^{5}$ Kirsty Docherty, ${ }^{3}$ David McIntosh, ${ }^{1}$ Penny McElhinney, ${ }^{6}$ \\ Marianne Nicolson, ${ }^{7}$ Donald C. McMillan, ${ }^{5}$ and Robert Milroy ${ }^{6}$
}

${ }^{1}$ Beatson Oncology Centre, 1053 Great Western Road, Glasgow G12 0YN, UK

${ }^{2}$ University of Aberdeen, Aberdeen, UK

${ }^{3}$ Inverclyde Royal Hospital, Inverclyde, UK

${ }^{4}$ Queen Margaret Hospital, Dunfermline, UK

${ }^{5}$ University of Glasgow, Glasgow, UK

${ }^{6}$ Glasgow Royal Infirmary, Glasgow, UK

${ }^{7}$ Aberdeen Royal Infirmary, Aberdeen, UK

Correspondence should be addressed to Derek Grose; derek_grose@hotmail.com

Received 27 August 2013; Revised 20 December 2013; Accepted 24 December 2013; Published 5 March 2014

Academic Editor: Seiji Niho

Copyright (C) 2014 Derek Grose et al. This is an open access article distributed under the Creative Commons Attribution License, which permits unrestricted use, distribution, and reproduction in any medium, provided the original work is properly cited.

Background. Prediction of survival in patients diagnosed with lung cancer remains problematical. The aim of the present study was to examine the clinical utility of an established objective marker of the systemic inflammatory response, the Glasgow Prognostic Score, as the basis of risk stratification in patients with lung cancer. Methods. Between 2005 and 2008 all newly diagnosed lung cancer patients coming through the multidisciplinary meetings (MDTs) of four Scottish centres were included in the study. The details of 882 patients with a confirmed new diagnosis of any subtype or stage of lung cancer were collected prospectively. Results. The median survival was 5.6 months (IQR 4.8-6.5). Survival analysis was undertaken in three separate groups based on mGPS score. In the mGPS 0 group the most highly predictive factors were performance status, weight loss, stage of NSCLC, and palliative treatment offered. In the mGPS 1 group performance status, stage of NSCLC, and radical treatment offered were significant. In the mGPS 2 group only performance status and weight loss were statistically significant. Discussion. This present study confirms previous work supporting the use of mGPS in predicting cancer survival; however, it goes further by showing how it might be used to provide more objective risk stratification in patients diagnosed with lung cancer.

\section{Introduction}

Within Scotland lung cancer remains the commonest cause of cancer related death [1]. The prognosis is bleak with the median survival in advanced disease around four months from diagnosis [1]. Survival compares unfavourably with other European countries and the USA $[1,2]$. It has often been felt that the Scottish lung cancer population has more comorbidity with poorer performance status thus presenting fewer tolerable therapeutic options.

It is difficult to quantify the complex nature of patient frailty to provide a degree of objective assessment of fitness
[3] and as a result prediction of survival in patients diagnosed with lung cancer remains problematical. Currently, prognosis is based upon a combination of stage of disease and performance status although other factors such as weight loss have been identified in the advanced cancer setting [4-6]. However, these host factors (weight loss and performance status) included in clinical decisions are recognised to be subjective in nature.

Recent work shows that the effect of systemic inflammation is detrimental in terms of outcome in cancer in general $[7,8]$ and in lung cancer specifically $[9-16]$. The combination 
TABLE 1: The Glasgow Prognostic Scores (online only).

\begin{tabular}{lc}
\hline & Score \\
\hline Glasgow Prognostic Score $(\mathrm{GPS})$ & \\
$\mathrm{CRP} \leq 10 \mathrm{mg} / \mathrm{L}$ and albumin $\geq 35 \mathrm{~g} / \mathrm{L}$ & 0 \\
$\mathrm{CRP}>10 \mathrm{mg} / \mathrm{L}$ or albumin $<35 \mathrm{~g} / \mathrm{L}$ & 1 \\
$\mathrm{CRP}>10 \mathrm{mg} / \mathrm{L}$ and albumin $<35 \mathrm{~g} / \mathrm{L}$ & 2 \\
Modified Glasgow Prognostic Score $(\mathrm{mGPS})$ & 0 \\
$\mathrm{CRP} \leq 10 \mathrm{mg} / \mathrm{L}$ and albumin $\geq 35 \mathrm{~g} / \mathrm{L}$ & 0 \\
$\mathrm{CRP} \leq 10 \mathrm{mg} / \mathrm{L}$ and albumin $<35 \mathrm{~g} / \mathrm{L}$ & 1 \\
$\mathrm{CRP}>10 \mathrm{mg} / \mathrm{L}$ & 2 \\
$\mathrm{CRP}>10 \mathrm{mg} / \mathrm{L}$ and albumin $<35 \mathrm{~g} / \mathrm{L}$ &
\end{tabular}

of C-reactive protein and albumin when combined to calculate the modified Glasgow Prognostic Score (Table 1) has been previously validated as an independent predictor of survival [17].

The aim of the present study was to examine the clinical utility of this established objective marker of the systemic inflammatory response, the modified Glasgow Prognostic Score (mGPS), as the basis of risk stratification in patients with lung cancer.

\section{Patients and Methods}

Four Scottish centres were included in the study: Aberdeen, Glasgow (Stobhill), Inverclyde, and West Fife. Over a defined period from 2005 to 2008 all newly diagnosed lung cancer patients coming through the regional multidisciplinary meetings (MDTs) were included in the study. In total the details of 882 patients were collected prospectively.

At the time of the patient discussion at the MDT annoymised details were entered into a specifically designed Microsoft Access database. Patient demographics and baseline characteristics (age, sex, postcode, and smoking history), PS (at time of presentation in addition to that six months prior to attendance as estimated by clinicians on questioning patients about fitness), weight loss, laboratory parameters (C-reactive protein, albumin, and ventilatory function), tumour stage and histology, and primary treatment proposed by the MDT were all recorded. If the treatment proposed varied from the 2005 Scottish Intercollegiate Guidelines Network (SIGN) guidelines [18] on lung cancer management the reasons why were also recorded (i.e., age, poor PS, comorbidity, size of tumour, etc.). All four MDTs had input from an oncologist and thoracic surgeon and thus we could be confident of accuracy of the clinical management decision. Details of the study design have previously been published [19].

Information on date of death was obtained via survival analysis undertaken by the Information Service Division (ISD) of NHS Scotland. Death records were complete until 1 June 2011, which served as the censor date for those alive.

2.1. Socioeconomic Status. Information on patients' individual educational or occupational social class was not available, and postcode of residence was used to identify the 2006
TABLE 2: Baseline characteristics of patients with lung cancer $(n=$ 882).

\begin{tabular}{|c|c|}
\hline Parameter & \\
\hline Age (years) & $72(31-94)$ years \\
\hline \multicolumn{2}{|l|}{ Sex } \\
\hline Male & $487(55 \%)$ \\
\hline Female & $395(45 \%)$ \\
\hline \multicolumn{2}{|l|}{ Smoking } \\
\hline Ever smoked & $94 \%$ \\
\hline Mean pack (years) & 44 years \\
\hline \multicolumn{2}{|l|}{ Centre } \\
\hline Aberdeen & $294(34 \%)$ \\
\hline Fife & $132(15 \%)$ \\
\hline Stobhill & $245(32 \%)$ \\
\hline Inverclyde & $161(19 \%)$ \\
\hline \multicolumn{2}{|l|}{ Deprivation (quintile) } \\
\hline Most deprived & $267(30 \%)$ \\
\hline 2.00 & $127(14 \%)$ \\
\hline 3.00 & $251(29 \%)$ \\
\hline 4.00 & $175(20 \%)$ \\
\hline Most affluent & $62(7 \%)$ \\
\hline \multicolumn{2}{|l|}{ Performance status } \\
\hline 0 & $101(11 \%)$ \\
\hline 1 & $312(35 \%)$ \\
\hline 2 & $285(32 \%)$ \\
\hline 3 & $154(17 \%)$ \\
\hline 4 & $30(3 \%)$ \\
\hline \multicolumn{2}{|l|}{ Stage } \\
\hline NSCLC I & $66(7 \%)$ \\
\hline NSCLC II & $43(5 \%)$ \\
\hline NSCLC St IIIa & $48(5 \%)$ \\
\hline NSCLC St IIIb & $140(16 \%)$ \\
\hline NSCLC St IV & $234(26 \%)$ \\
\hline SCLC limited & $33(4 \%)$ \\
\hline SCLC extensive & $82(9 \%)$ \\
\hline No histology & $210(24 \%)$ \\
\hline \multicolumn{2}{|l|}{ Treatment } \\
\hline Radical & $193(27 \%)$ \\
\hline Palliative & $533(73 \%)$ \\
\hline \multicolumn{2}{|l|}{ mGPS } \\
\hline 0 & $213(24 \%)$ \\
\hline 1 & $290(32 \%)$ \\
\hline 2 & $210(24 \%)$ \\
\hline Missing data & $169(19 \%)$ \\
\hline 12 -month survival rate $\%(\mathrm{SE})$ & $30 \%(2)$ \\
\hline
\end{tabular}

Scottish Index of Multiple Deprivation (SIMD) ranking as a proxy indicator of their socioeconomic circumstances [20]. The 2006 SIMD is a validated area-based index that uses 37 indicators in seven domains to rank 6505 small geographic areas in Scotland (data zones) from 1 (most deprived) to 6505 (least deprived). These can be subsequently grouped into quintiles, and we used Scottish national quintiles. 
TABLE 3: The relationship between the mGPS and clinicopathological characteristics in patients with lung cancer.

\begin{tabular}{|c|c|c|c|c|}
\hline \multirow{2}{*}{ Demographic } & \multicolumn{3}{|c|}{ mGPS } & \multirow{2}{*}{$P$ value (chi-square test) } \\
\hline & $0(n=213)$ & $1(n=290)$ & $2(n=218)$ & \\
\hline \multicolumn{5}{|l|}{ Age } \\
\hline$<60 / 60-69 / 70-79 / \geq 80$ years & $33 / 71 / 89 / 28$ & $44 / 87 / 119 / 54$ & $34 / 57 / 91 / 49$ & 0.064 \\
\hline \multicolumn{5}{|l|}{ Sex } \\
\hline Male/female & $115 / 108$ & $174 / 130$ & $133 / 98$ & 0.201 \\
\hline \multicolumn{5}{|l|}{ Centre } \\
\hline Aber/Fife/Stob/Inver & $98 / 10 / 77 / 38$ & $146 / 25 / 66 / 67$ & $43 / 16 / 126 / 46$ & $<0.001$ \\
\hline \multicolumn{5}{|l|}{ Deprivation } \\
\hline Most-least (quintile) & $68 / 24 / 71 / 39 / 21$ & $75 / 47 / 75 / 77 / 30$ & $111 / 21 / 70 / 20 / 9$ & $<0.001$ \\
\hline \multicolumn{5}{|l|}{ Smoke (pack years) } \\
\hline $\mathrm{NS} /<20 / 20-60 />60$ & $21 / 24 / 126 / 37$ & $11 / 33 / 177 / 69$ & $13 / 21 / 128 / 57$ & 0.014 \\
\hline \multicolumn{5}{|l|}{ Performance status } \\
\hline $0 / 1 / 2 / 3 / 4$ & $42 / 96 / 60 / 22 / 3$ & $26 / 130 / 105 / 40 / 3$ & $5 / 51 / 88 / 66 / 21$ & $<0.001$ \\
\hline \multicolumn{5}{|l|}{ Weight loss (\%) } \\
\hline $0 /<5 / 5-10 />10$ & $147 / 24 / 12 / 38$ & $146 / 36 / 13 / 109$ & $79 / 45 / 33 / 73$ & $<0.001$ \\
\hline \multicolumn{5}{|l|}{ FEV1 (\%) } \\
\hline$<80 / 61-80 / 40-60 /<40$ & $138 / 31 / 45 / 7$ & $181 / 48 / 53 / 22$ & $130 / 33 / 47 / 17$ & 0.126 \\
\hline \multicolumn{5}{|l|}{ Local symptoms } \\
\hline No/yes & $36 / 127$ & $18 / 222$ & $29 / 137$ & 0.246 \\
\hline \multicolumn{5}{|l|}{ Tumour stage of NSCLC } \\
\hline I/II/IIIa/IIIb/IV & $32 / 11 / 7 / 38 / 38$ & $15 / 19 / 20 / 56 / 84$ & $7 / 5 / 12 / 36 / 79$ & $<0.001$ \\
\hline \multicolumn{5}{|l|}{ Tumour stage of SCLC } \\
\hline Limited/extensive & $13 / 21$ & $10 / 32$ & $8 / 18$ & 0.471 \\
\hline \multicolumn{5}{|l|}{ Treatment } \\
\hline \multicolumn{5}{|l|}{ Radical treatment } \\
\hline Surgery/RT/no active & $26 / 9 / 38$ & $17 / 15 / 43$ & $4 / 2 / 18$ & $<0.001$ \\
\hline \multicolumn{5}{|l|}{ Palliative treatment } \\
\hline Chemo/RT/No active & $63 / 27 / 49$ & $107 / 58 / 55$ & $50 / 49 / 75$ & $<0.001$ \\
\hline \multicolumn{5}{|l|}{ Survival } \\
\hline Alive/dead & $34 / 181$ & $16 / 274$ & $8 / 211$ & 0.003 \\
\hline 12-month survival \% (SE) & $46(4)$ & $16(2)$ & $14(3)$ & $<0.001$ \\
\hline
\end{tabular}

2.2. GPS/mGPS. A venous blood sample was obtained at diagnosis for measurement of CRP concentration and albumin. The coefficient of variation for these methods over the range of measurement was less than $5 \%$, as established by routine quality control procedures. The GPS was constructed as previously described (Table 1) [21, 22]. In brief, CRP more than $10 \mathrm{mg} / \mathrm{L}$ and albumin less than $35 \mathrm{~g} / \mathrm{dL}$ were each given a score of 1 . The GPS was calculated as 0,1 , or 2 . Since hypoalbuminaemia alone in the absence of an increased CRP level did not confer a poorer cancer-specific survival in all patients with cancer $[8,22]$, the GPS was modified to assign a score of 0 in patients with hypoalbuminaemia alone (Table 1 ) [23].

A number of recent studies have supported the use of mGPS in predicting outcome both in lung cancer and other tumour types [9-17]. As such it was our intention to stratify the group by mGPS and then analyse the impact of more conventional staging methods such as TNM stage and performance status.
2.3. Ethics. The audit was discussed with the local ethics committee, and since it was classed as a health service clinical practice audit, formal ethical approval was deemed not to be necessary.

2.4. Statistics. All statistical testing was conducted at the $5 \%$ level so $95 \%$ confidence intervals (CI) are reported throughout. Unless otherwise stated, medians and interquartile range (IQR) are used. The survival time defined as the number of months from study entry until death or if alive at follow-up date was calculated. Univariate survival analysis was carried out using the Kaplan-Meier method and the log rank test. Survival analysis was carried out using Cox's proportionalhazards model and hazard ratios (HR) were calculated. Multivariate survival analysis was performed using a stepwise backward procedure to derive a final model of the variables that had a significant independent relationship with survival. To remove a variable from the model, the corresponding $P$ value had to be $>0.10$. 


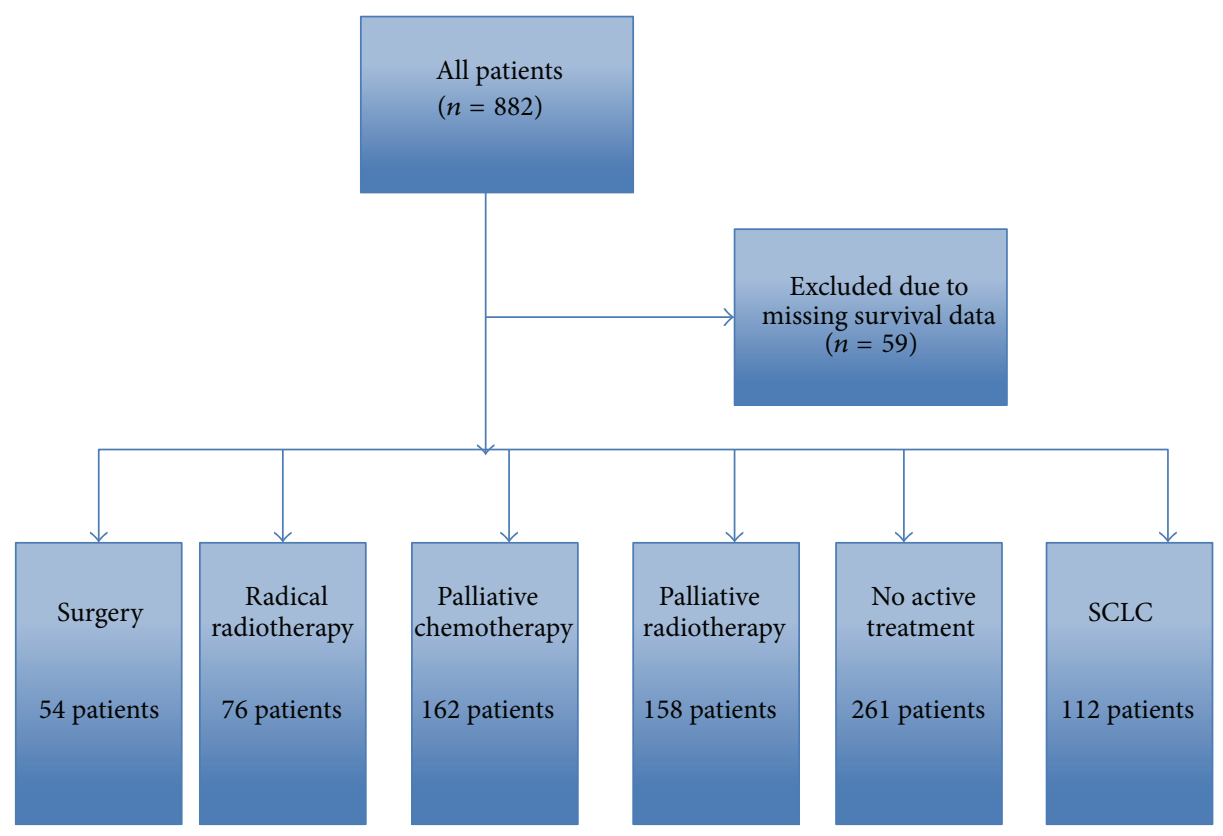

FIGURE 1: Flow chart of patient selection process.

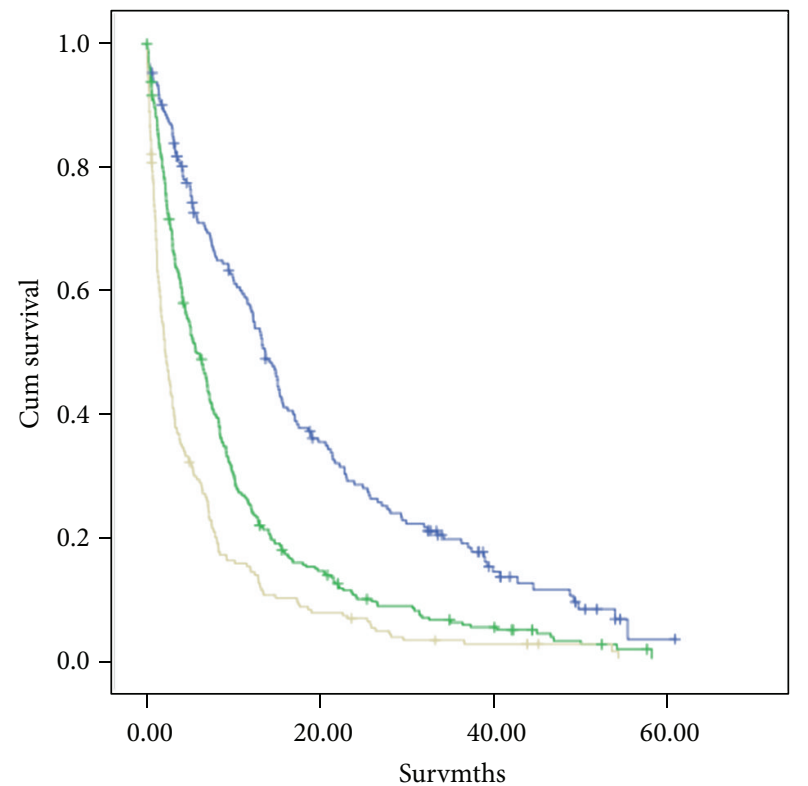

FIgURE 2: The relationship between GPS ( $0-2$, from top to bottom) and survival. GPS 0 versus 1 ( $\log \operatorname{rank} P<0.001)$, GPS 1 versus 2 $(\log \operatorname{rank} P<0.001)$.

Statistical analyses were performed using SPSS v19.0 (SPSS Inc., Chicago, IL).

\section{Results}

In total, 882 patients from a number of different treatment groups were included in the study, comprising 297 from Aberdeen, 136 from West Fife, 285 from Glasgow, and 164

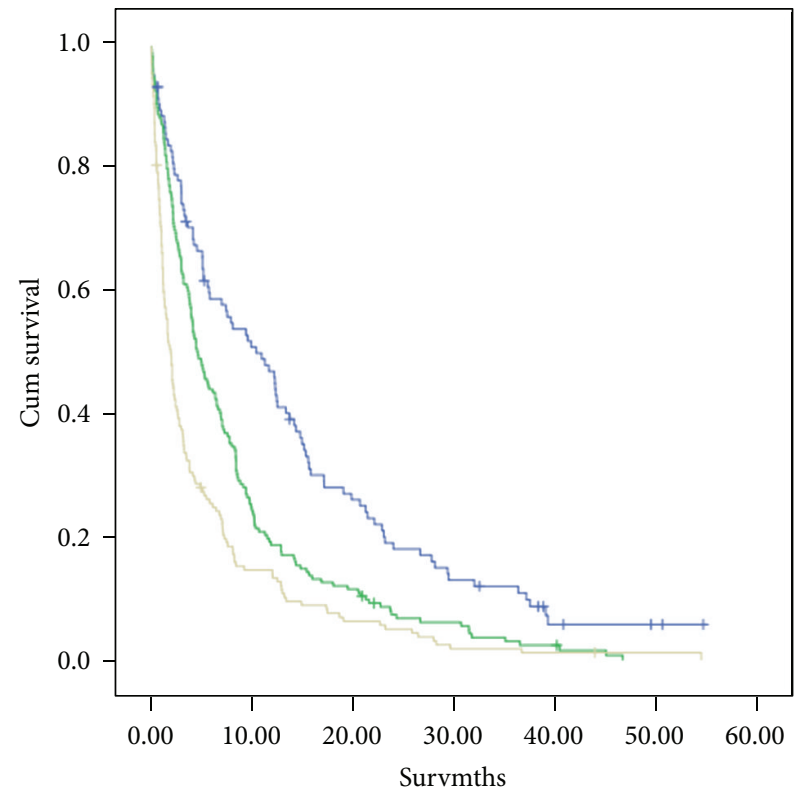

FIgURE 3: The relationship between mGPS ( $0-2$, from top to bottom) and survival. mGPS 0 versus 1 ( $\log \operatorname{rank} P<0.001)$, mGPS 1 versus $2(\log \operatorname{rank} P<0.001)$.

from Inverclyde composing; 59 patients were excluded from the study due to missing survival data (Figure 1). Baseline characteristics are shown in Table 2. The median age of participants was 72 years old. The majority were male, current or ex-smokers, and of good performance status with advanced disease and had treatment with palliative intent.

Of the patients $24 \%$ were diagnosed on the basis of clinical examination and radiological investigations alone 
TABLE 4: The relationship between parameters and survival in patients with mGPS $=0(n=213)$.

\begin{tabular}{|c|c|c|c|c|c|}
\hline \multirow{2}{*}{ Parameter } & \multirow{2}{*}{$\begin{array}{c}\text { Patients } \\
N\end{array}$} & \multicolumn{2}{|c|}{ Univariate } & \multicolumn{2}{|c|}{ Multivariate } \\
\hline & & HR (95\% CI) & $P$ value & HR (95\% CI) & $P$ value \\
\hline \multicolumn{6}{|l|}{ Age } \\
\hline$<60 / 60-69 / 70-79 / \geq 80$ years & $33 / 71 / 89 / 28$ & $1.16(0.98-1.37)$ & 0.077 & - & \\
\hline \multicolumn{6}{|l|}{ Sex } \\
\hline Male & 115 & 1 & - & - & - \\
\hline Female & 108 & $0.81(0.61-1.09)$ & 0.169 & - & - \\
\hline \multicolumn{6}{|l|}{ Centre } \\
\hline Aberdeen & 98 & 1 & 0.068 & - & - \\
\hline Fife & 10 & $2.72(1.40-5.29)$ & - & - & - \\
\hline Stobhill & 77 & $1.00(0.72-1.41)$ & - & - & - \\
\hline Inverclyde & 38 & $1.13(0.75-1.70)$ & - & - & - \\
\hline \multicolumn{6}{|c|}{ Deprivation $($ most deprived $=1$, least deprived $=5$ ) } \\
\hline $1 / 2 / 3 / 4 / 5$ & $68 / 24 / 71 / 39 / 21$ & $0.94(0.85-1.05)$ & 0.299 & - & - \\
\hline \multicolumn{6}{|c|}{ Smoking history (NS = never smoker, otherwise pack years) } \\
\hline $\mathrm{NS} /<20 / 20-60 />60$ & $21 / 24 / 126 / 37$ & $0.93(0.77-1.12)$ & 0.467 & - & - \\
\hline \multicolumn{6}{|l|}{ Performance status } \\
\hline $0 / 1 / 2 / 3 / 4$ & $42 / 96 / 60 / 22 / 3$ & $1.76(1.47-2.11)$ & $<0.001$ & $1.69(1.39-2.06)$ & $<0.001$ \\
\hline \multicolumn{6}{|l|}{ Weight loss (\% body weight) } \\
\hline $0 /<5 / 5-10 />10$ & $147 / 24 / 12 / 38$ & $1.21(1.08-1.37)$ & 0.002 & $1.18(1.04-1.33)$ & 0.009 \\
\hline \multicolumn{6}{|l|}{ FEV1 (\%) } \\
\hline$>80 / 80-60 / 59-40 /<40$ & $138 / 31 / 45 / 7$ & $0.94(0.80-1.12)$ & 0.515 & - & - \\
\hline \multicolumn{6}{|l|}{ Local symptoms } \\
\hline No/yes & $36 / 127$ & $1.38(0.91-2.09)$ & 0.124 & - & - \\
\hline \multicolumn{6}{|l|}{ Stage } \\
\hline \multicolumn{6}{|l|}{ NSCLC } \\
\hline I/II/IIIa/IIIb/IV & $32 / 11 / 7 / 38 / 38$ & $1.38(1.25-1.53)$ & $<0.001$ & $1.06(1.01-1.23)$ & 0.017 \\
\hline \multicolumn{6}{|l|}{ SCLC } \\
\hline Limited/extensive & $13 / 21$ & $1.05(0.97-1.14)$ & 0.228 & - & - \\
\hline \multicolumn{6}{|l|}{ Treatment } \\
\hline \multicolumn{6}{|l|}{ Radical } \\
\hline BSC/surgery/RT & $37 / 26 / 8$ & $0.61(0.48-0.78)$ & 0.001 & - & - \\
\hline \multicolumn{6}{|l|}{ Palliative } \\
\hline Chemo/RT/BSC & $59 / 27 / 47$ & $1.22(1.01-1.46)$ & 0.039 & $1.30(1.08-1.55)$ & 0.004 \\
\hline
\end{tabular}

and without histological evidence. This compares favourably with the National Lung Cancer Audit data [24], which had a median rate of $37 \%$ of patients who did not have histological confirmation of lung cancer.

Most had an elevated mGPS. The median followup for survivors was 24.5 months (4.6-40.8). The median overall survival was 5.6 months (4.8-6.5). The 12-month survival rate was 30\% (SE 2\%).

Survival analysis using both GPS and mGPS was undertaken (Figures 2 and 3). Both were highly significantly associated with survival. Since the mGPS has been most extensively validated and readily extrapolated from previous work using C-reactive protein alone $[7,17]$, it was used in the remainder of the analysis and to stratify the three groups.

The relationship between the mGPS and clinicopathological characteristics is shown in Table 3. There were 213 patients in the mGPS score of 0 group, 290 patients in the mGPS score of 1 group, and 218 patients in the mGPS score of 2 group. The mGPS was associated with increasing deprivation $(P<0.001)$, pack years smoking $(P<0.001)$, poorer performance status $(P<0.001)$, more weight loss $(P<0.001)$, more advanced disease $(P<0.001)$, more radical treatment $(P<0.001)$, and poorer survival $(P<0.001)$.

The relationship between the clinicopathological characteristics and survival in patients with an mGPS of 0 is shown in Table 4. The median survival was 13.2 (11.2-18.9) months. On univariate survival analysis, performance status $(P<$ $0.001)$, weight loss $(P<0.01)$, stage of NSCLC $(P<0.001)$, radical treatment offered $(P<0.01)$, and palliative treatment offered $(P<0.05)$ were significantly associated with survival. On multivariate analysis, performance status (HR 1.69, 95\% CI 1.39-2.06, and $P<0.001$ ), weight loss (HR 1.18, 95\% CI $1.04-1.33$, and $P=0.009$ ), stage of NSCLC (HR 1.06, 95\% CI $1.01-1.23$, and $P=0.017$ ) and palliative treatment offered (HR $1.30,95 \%$ CI $1.08-1.55$, and $P=0.004$ ) were independently associated with survival. 
TABLE 5: The relationship between parameters and survival in patients with mGPS $=1(n=290)$.

\begin{tabular}{|c|c|c|c|c|c|}
\hline \multirow{2}{*}{ Parameter } & \multirow{2}{*}{$\begin{array}{c}\text { Patients } \\
\qquad N\end{array}$} & \multicolumn{2}{|c|}{ Univariate } & \multicolumn{2}{|c|}{ Multivariate } \\
\hline & & $\operatorname{HR}(95 \% \mathrm{CI})$ & $P$ value & $\operatorname{HR}(95 \% \mathrm{CI})$ & $P$ value \\
\hline \multicolumn{6}{|l|}{ Age } \\
\hline$<60 / 60-69 / 70-79 / \geq 80$ & $33 / 71 / 89 / 28$ & $1.24(1.09-1.40)$ & 0.001 & - & - \\
\hline \multicolumn{6}{|l|}{ Sex } \\
\hline Male & 174 & 1 & 0.171 & - & - \\
\hline Female & 130 & $0.84(0.66-1.08)$ & - & - & - \\
\hline \multicolumn{6}{|l|}{ Centre } \\
\hline Aberdeen & 145 & 1 & 0.425 & - & - \\
\hline Fife & 23 & $0.89(0.55-1.43)$ & - & - & - \\
\hline Stobhill & 55 & $0.99(0.72-1.36)$ & - & - & - \\
\hline Inverclyde & 67 & $1.23(0.92-1.66)$ & - & - & - \\
\hline \multicolumn{6}{|c|}{ Deprivation (quintile) (most deprived $=1$, least deprived $=5$ ) } \\
\hline $1 / 2 / 3 / 4 / 5$ & $75 / 47 / 75 / 77 / 30$ & $0.99(0.90-1.08)$ & 0.777 & - & - \\
\hline \multicolumn{6}{|c|}{ Smoking history (NS = never smoker, otherwise pack years) } \\
\hline $\mathrm{NS} /<20 / 20-60 />60$ & $11 / 33 / 177 / 69$ & $1.02(0.86-1.22)$ & 0.792 & - & - \\
\hline \multicolumn{6}{|l|}{ Performance status } \\
\hline $0 / 1 / 2 / 3 / 4$ & $26 / 130 / 105 / 40 / 3$ & $1.83(1.57-2.14)$ & $<0.001$ & $1.81(1.55-2.13)$ & $<0.001$ \\
\hline \multicolumn{6}{|l|}{ Weight loss (\% body weight) } \\
\hline $0 /<5 / 5-10 />10$ & $181 / 48 / 53 / 22$ & $1.15(1.06-1.25)$ & 0.001 & - & - \\
\hline \multicolumn{6}{|l|}{ FEV1 (\%) } \\
\hline$>80 / 80-60 / 59-40 /<40$ & $138 / 31 / 45 / 7$ & $0.94(0.83-1.06)$ & 0.313 & - & - \\
\hline \multicolumn{6}{|l|}{ Local symptoms } \\
\hline No/yes & $18 / 222$ & $1.60(0.91-2.80)$ & 0.105 & - & - \\
\hline \multicolumn{6}{|l|}{ Stage } \\
\hline \multicolumn{6}{|l|}{ NSCLC } \\
\hline I/II/IIIa/IIIb/IV & $15 / 19 / 20 / 56 / 84$ & $1.31(1.19-1.45)$ & $<0.001$ & $1.08(1.03-1.13)$ & 0.002 \\
\hline \multicolumn{6}{|l|}{ SCLC } \\
\hline Limited/extensive & $10 / 32$ & $0.51(0.23-1.11)$ & 0.091 & - & - \\
\hline \multicolumn{6}{|l|}{ Treatment } \\
\hline \multicolumn{6}{|l|}{ Radical } \\
\hline $\mathrm{BSC} /$ surgery/RT & $43 / 17 / 15$ & $0.55(0.41-0.72)$ & $<0.001$ & $0.70(0.52-0.94)$ & 0.017 \\
\hline \multicolumn{6}{|l|}{ Palliative } \\
\hline Chemo/RT/BSC & $107 / 58 / 55$ & $1.07(0.90-1.26)$ & 0.436 & - & - \\
\hline
\end{tabular}

The relationship between the clinico-pathological characteristics and survival in patients with an mGPS of 1 is shown in Table 5. The median survival was 6.1 (4.9-7.3) months. On univariate survival analysis, decreased age $(P<0.01)$, performance status $(P<0.001)$, weight loss $(P<0.01)$, stage of NSCLC $(P<0.001)$, and radical treatment offered $(P<0.001)$ were significantly associated with survival. On multivariate analysis, performance status (HR 1.81, 95\% CI $1.55-2.13$, and $P<0.001$ ), stage of NSCLC (HR 1.08, 95\% CI 1.03-1.13, and $P<0.01$ ) and radical treatment offered (HR $0.70,95 \%$ CI $0.52-0.94$, and $P<0.05$ ) were independently associated with survival.

The relationship between the clinico-pathological characteristics and survival in patients with an mGPS of 2 is shown in Table 6. The median survival was 2.1 (1.5-2.7) months. On univariate survival analysis, centre $(P<0.01)$, performance status $(P<0.001)$, weight loss $(P<0.001)$, stage of NSCLC
$(P<0.001)$, and radical treatment offered $(P<0.01)$ were significantly associated with survival. On multivariate analysis, only performance status (HR 1.44, 95\% CI 1.21-1.71, and $P<0.001$ ) and weight loss (HR 1.13, 95\% CI 1.00-1.28, and $P<0.05$ ) were independently associated with survival.

The relationship between mGPS, performance status, and survival at 1 year is shown in Table 7 . When used in combination survival at 1 year varied from $72 \%$ (mGPS 0 , PS 0 ) to $6 \%$ (mGPS 2, PS 3 ). The numbers in the PS 4 subgroup were too small to calculate accurately a survival rate.

The relationship between mGPS, TNM stage (NSCLC patients only), and survival at 1 year is shown in Table 8 . Survival varied from $69 \%$ (mGPS 0 , Stage I NSCLC) to $2 \%$ (mGPS 2, Stage IV NSCLC).

To stratify for stage, the relationship between mGPS and PS and survival at 3 months for those patients with advanced NSCLC (St IIIb/IV) is shown in Table 9. 
TABLE 6: The relationship between parameters and survival in patients with mGPS $=2(n=218)$.

\begin{tabular}{|c|c|c|c|c|c|}
\hline \multirow{2}{*}{ Parameter } & \multirow{2}{*}{$\begin{array}{c}\text { Patients } \\
\qquad N\end{array}$} & \multicolumn{2}{|c|}{ Univariate } & \multicolumn{2}{|c|}{ Multivariate } \\
\hline & & HR (95\% CI) & $P$ value & HR (95\% CI) & $P$ value \\
\hline \multicolumn{6}{|l|}{ Age } \\
\hline$<60 / 60-69 / 70-79 / \geq 80$ & $34 / 57 / 91 / 49$ & $1.13(0.98-1.30)$ & 0.084 & - & - \\
\hline \multicolumn{6}{|l|}{ Sex } \\
\hline Male & 133 & 1 & 0.136 & - & - \\
\hline Female & 98 & $0.81(0.61-1.07)$ & - & - & - \\
\hline \multicolumn{6}{|l|}{ Centre } \\
\hline Aberdeen & 43 & 1 & 0.002 & - & - \\
\hline Fife & 16 & $1.71(0.95-3.06)$ & - & - & - \\
\hline Stobhill & 114 & $0.64(0.45-0.92)$ & - & - & - \\
\hline Inverclyde & 45 & $0.88(0.57-1.35)$ & - & - & - \\
\hline \multicolumn{6}{|c|}{ Deprivation (quintile) (most deprived $=1$, least deprived $=5$ ) } \\
\hline $1 / 2 / 3 / 4 / 5$ & $111 / 21 / 70 / 20 / 9$ & $1.05(0.94-1.17)$ & 0.408 & - & - \\
\hline \multicolumn{6}{|c|}{ Smoking history (NS = never smoker, otherwise pack years) } \\
\hline $\mathrm{NS} /<20 / 20-60 />60$ & $13 / 21 / 128 / 57$ & $0.83(0.69-1.00)$ & 0.062 & - & - \\
\hline \multicolumn{6}{|l|}{ Performance status } \\
\hline $0 / 1 / 2 / 3 / 4$ & $5 / 51 / 88 / 66 / 21$ & $1.51(1.30-1.76)$ & $<0.001$ & $1.44(1.21-1.71)$ & $<0.001$ \\
\hline \multicolumn{6}{|l|}{ Weight loss (\% body weight) } \\
\hline $0 /<5 / 5-10 />10$ & $79 / 45 / 33 / 73$ & $1.25(1.11-1.40)$ & $<0.001$ & $1.13(1.00-1.28)$ & 0.047 \\
\hline \multicolumn{6}{|l|}{ FEV1 (\%) } \\
\hline$>80 / 80-60 / 59-40 /<40$ & $130 / 33 / 47 / 17$ & $0.88(0.77-1.01)$ & 0.073 & - & - \\
\hline \multicolumn{6}{|l|}{ Local symptoms } \\
\hline No/Yes & $29 / 137$ & $1.51(0.98-2.33)$ & 0.063 & - & - \\
\hline \multicolumn{6}{|l|}{ Stage } \\
\hline \multicolumn{6}{|l|}{ NSCLC } \\
\hline I/II/IIIa/IIIb/IV & $7 / 5 / 12 / 36 / 79$ & $1.32(1.15-1.50)$ & $<0.001$ & - & - \\
\hline \multicolumn{6}{|l|}{ SCLC } \\
\hline Limited/extensive & $8 / 18$ & $1.01(0.91-1.12)$ & 0.826 & - & - \\
\hline \multicolumn{6}{|l|}{ Treatment } \\
\hline \multicolumn{6}{|l|}{ Radical } \\
\hline BSC/surgery/RT & $18 / 2 / 4$ & $0.52(0.33-0.83)$ & 0.006 & - & - \\
\hline \multicolumn{6}{|l|}{ Palliative } \\
\hline Chemo/RT/BSC & $50 / 49 / 75$ & $0.92(0.78-1.10)$ & 0.364 & - & - \\
\hline
\end{tabular}

Survival varied from $100 \%$ (mGPS 0 , PS 0) to $23 \%$ (mGPS 2, PS 3). The number of patients in the PS 4 group was too small to accurately calculate survival.

This group was then further stratified to take into account the treatment offered. The relationship between mGPS and PS at 3 months for those patients with advanced NSCLC (St IIIb/IV) undergoing palliative chemotherapy is shown in Table 10. Survival varied from $92 \%$ (mGPS 0, PS 1) to $50 \%$ (mGPS 2, PS 2). The numbers of patients in the PS 0 and 4 groups were too small to accurately calculate survival.

\section{Discussion}

The results of the present study show for the first time that, in a large cohort of patients with lung cancer and using the mGPS as an objective basis for the prediction of survival, significant factors associated with survival varied significantly. Only performance status and to a lesser extent
TABLE 7: The relationship between mGPS and PS and 12-month survival rate $(\%, \mathrm{SE})$.

\begin{tabular}{lcccc}
\hline PS & \multicolumn{3}{c}{ mGPS } & $\begin{array}{c}\text { Total number } \\
\text { of patients }\end{array}$ \\
\hline 0 & $72 \%(7)$ & $50 \%(10)$ & $20 \%(18)$ & 71 \\
1 & $65 \%(5)$ & $31 \%(4)$ & $30 \%(7)$ & 259 \\
2 & $49 \%(7)$ & $19 \%(4)$ & $16 \%(4)$ & 245 \\
3 & $9 \%(6)$ & $5 \%(4)$ & $6 \%(3)$ & 122 \\
4 & $\mathrm{NC}$ & $\mathrm{NC}$ & $\mathrm{NC}$ & 20 \\
$\begin{array}{l}\text { Total number } \\
\text { of patients }\end{array}$ & 212 & 290 & 218 & - \\
\hline
\end{tabular}

NC: not calculated where $N<10$.

tumour stage were consistently shown to have independent prognostic value. Furthermore, the combination of the mGPS 
TABLE 8: The relationship between mGPS and TNM stage (NSCLC only) and 12-month survival rate (\%, SE).

\begin{tabular}{lcccc}
\hline Stage & \multicolumn{3}{c}{ mGPS } & $\begin{array}{c}\text { Total number } \\
\text { of patients }\end{array}$ \\
\hline I & $69 \%(19)$ & $28 \%(12)$ & NC & 62 \\
II & $37 \%(14)$ & $17 \%(9)$ & NC & 47 \\
IIIa & $20 \%(13)$ & $42 \%(10)$ & $0 \%$ & 53 \\
IIIb & $20 \%(6)$ & $6 \%(3)$ & $14 \%(5)$ & 154 \\
IV & $5 \%(3)$ & $4 \%(2)$ & $2 \%(2)$ & 261 \\
$\begin{array}{l}\text { Total number } \\
\text { of patients }\end{array}$ & 153 & 225 & 173 & - \\
\hline
\end{tabular}

NC: not calculated where $N<10$.

TABle 9: The relationship between mGPS and PS and 3-month survival rate $(\%, \mathrm{SE})$ in patients with TNM stage IIIb/IV NSCLC $(n=374)$.

\begin{tabular}{lcccc}
\hline PS & \multicolumn{3}{c}{ mGPS } & $\begin{array}{c}\text { Total number } \\
\text { of patients }\end{array}$ \\
\hline 0 & 0 & 1 & 2 & 28 \\
1 & $100 \%(0)$ & $92 \%(8)$ & $100 \%(0)$ & 119 \\
2 & $94 \%(4)$ & $73 \%(6)$ & $55 \%(9)$ & 105 \\
3 & $65 \%(11)$ & $62 \%(7)$ & $43 \%(8)$ & 55 \\
4 & $\mathrm{NC}$ & $29 \%(11)$ & $23 \%(8)$ & 7 \\
$\begin{array}{l}\text { Total number } \\
\text { of patients }\end{array}$ & $\mathrm{NC}$ & $\mathrm{NC}$ & $\mathrm{NC}$ & - \\
\hline
\end{tabular}

NC: not calculated where $N<10$.

TABLE 10: The relationship between mGPS and PS and 3-month survival rate $(\%, \mathrm{SE})$ in patients with TNM stage IIIb/IV NSCLC and receiving palliative chemotherapy $(n=138)$.

\begin{tabular}{lcccc}
\hline PS & \multicolumn{3}{c}{ mGPS } & $\begin{array}{c}\text { Total number } \\
\text { of patients }\end{array}$ \\
\hline 0 & 0 & 1 & 2 & 13 \\
1 & $\mathrm{NC}$ & $\mathrm{NC}$ & $\mathrm{NC}$ & 60 \\
2 & $92 \%(7)$ & $74 \%(8)$ & $54 \%(14)$ & 33 \\
3 & $\mathrm{NC}$ & $69 \%(12)$ & $50 \%(16)$ & 12 \\
4 & $\mathrm{NC}$ & $\mathrm{NC}$ & $\mathrm{NC}$ & 0 \\
$\begin{array}{l}\text { Total number } \\
\text { of patients }\end{array}$ & $\mathrm{NC}$ & $\mathrm{NC}$ & $\mathrm{NC}$ & - \\
\hline
\end{tabular}

NC: not calculated where $N<10$.

with either performance status or tumour stage effectively stratified the likely outcome in these patients. Therefore, this simple scheme based on objective criteria provides a new readily applicable approach to the routine clinical evaluation of patients with lung cancer.

In the present study it was of interest that weight loss, a well recognised poor prognostic factor, was inconsistently prognostic when included in the analysis with mGPS and performance status. This may suggest that much of the prognostic value of weight loss is attributable to the activation of the systemic inflammatory response and to the progressive loss of lean tissue leading to nutritional and functional decline [7]. Indeed, activation of the systemic inflammatory response resulted in a marked reduction in median survival of 13 months (mGPS 0) to 2 months (mGPS 2) independent of treatment received. This would suggest that the allocation of treatment was suboptimal and it may be that treatment allocated on a more objective scheme as proposed above will result in improved outcomes in all patients. For example, in those patients with mGPS of 2, neither stage nor treatment had independent prognostic value and therefore it would appear that such poor prognosis patients derive little benefit from standard anticancer treatment. In particular a very honest appraisal of both benefits and toxicities of any treatment should be made with the patient irrespective of their tumour stage [25]. However it must be noted that the very small numbers of patients in these groups (e.g., only 2 patients underwent surgery and 4 underwent radical radiotherapy) make it very difficult to interpret and further studies looking only at radically treatable patients are advised.

The relationship between poor survival and systemic inflammation (the mGPS) remains poorly understood, but it is likely to represent an objective marker of the chronic activation of the innate immune response with the consequent upregulation of proinflammatory cytokines and growth factors and the resultant cancer cachexia [26-31].

It is clear that, in Scotland, lung cancer continues to confer a very poor outcome with a median life expectancy of approximately 5 months. Even in early disease (TNM I/II NSCLC), with patients undergoing radical treatment with an expectation of cure $(10-15 \%$ of total number of patients within Scotland [32]) the 5-year survival is only around $30-60 \%$ [32]. The advent of more advanced imaging modalities such as PET-CT [18] has improved detection of occult metastasis leading to stage migration and less patients undergoing futile radical local treatment. Nevertheless, the present results highlight the importance of also staging the host systemic inflammatory response. The mGPS is a simple, cheap, and reproducible prognostic tool that has been shown to be a rational starting point for such work.

Since the initial work, a decade ago the combination of C-reactive protein and albumin, the Glasgow Prognostic Score (GPS/mGPS), has been shown to have independent prognostic value in more than 60 studies $(>30,000$ patients with cancer). This prognostic value has been demonstrated in a variety of clinical scenarios, in particular primary operable cancer [17].

A more recent study of apporximately 2,500 patients [33] and this present study have demonstrated that the mGPS has also clinical utility, together with performance status, in patients with advanced cancer.

In conclusion, the results of the present study confirm the independent prognostic value of the mGPS. In addition, it demonstrates the clinical utility of the mGPS combined with performance status to provide more objective risk stratification in patients diagnosed with lung cancer. 


\section{Conflict of Interests}

The authors declare that there is no conflict of interests regarding the publication of this paper.

\section{Acknowledgment}

The authors wish to acknowledge the support of the West of Scotland Lung Cancer Group in providing funding for the survival analysis of this study.

\section{References}

[1] F. Berrino, R. De Angelis, M. Sant et al., "Survival for eight major cancers and all cancers combined for European adults diagnosed in 1995-99: results of the EUROCARE-4 study," Lancet Oncology, vol. 8, no. 9, pp. 773-783, 2007.

[2] M. L. G. Janssen-Heijnen, G. Gatta, D. Forman, R. Capocaccia, and J. W. W. Coebergh, "Variation in survival of patients with lung cancer in Europe, 1985-1989," European Journal of Cancer, vol. 34, no. 14, pp. 2191-2196, 1998.

[3] M. Maltoni, A. Caraceni, C. Brunelli et al., "Prognostic factors in advanced cancer patients: evidence-based clinical recommendations-a study by the steering committee of the european association for palliative care," Journal of Clinical Oncology, vol. 23, no. 25, pp. 6240-6248, 2005.

[4] L. Martin, S. Watanabe, R. Fainsinger et al., "Prognostic factors in patients with advanced cancer: use of the patient-generated subjective global assessment in survival prediction," Journal of Clinical Oncology, vol. 28, no. 28, pp. 4376-4383, 2010.

[5] P. A. Glare, S. Eychmueller, and P. McMahon, "Diagnostic accuracy of the Palliative Prognostic score in hospitalized patients with advanced cancer," Journal of Clinical Oncology, vol. 22, no. 23, pp. 4823-4828, 2004.

[6] S. Gripp, S. Moeller, E. Bölke et al., "Survival prediction in terminally ill cancer patients by clinical estimates, laboratory tests, and self-rated anxiety and depression," Journal of Clinical Oncology, vol. 25, no. 22, pp. 3313-3320, 2007.

[7] D. C. McMillan, "Systemic inflammation, nutritional status and survival in patients with cancer," Current Opinion in Clinical Nutrition and Metabolic Care, vol. 12, no. 3, pp. 223-226, 2009.

[8] M. J. Proctor, D. S. Morrison, D. Talwar et al., "An inflammationbased prognostic score (mGPS) predicts cancer survival independent of tumour site: a Glasgow Inflammation Outcome Study," British Journal of Cancer, vol. 104, no. 4, pp. 726-734, 2011.

[9] S. Wilop, M. Crysandt, M. Bendel, A. H. Mahnken, R. Osieka, and E. Jost, "Correlation of C-reactive protein with survival and radiographic response to first-line platinum-based chemotherapy in advanced non-small cell lung cancer," Onkologie, vol. 31, no. 12, pp. 665-670, 2008.

[10] A. Koch, H. Fohlin, and S. Sörenson, "Prognostic significance of C-reactive protein and smoking in patients with advanced non-small cell lung cancer treated with first-line palliative chemotherapy," Journal of Thoracic Oncology, vol. 4, no. 3, pp. 326-332, 2009.

[11] B. Gagnon, M. Abrahamowicz, Y. Xiao et al., "Flexible modeling improves assessment of prognostic value of C-reactive protein in advanced non-small cell lung cancer," British Journal of Cancer, vol. 102, no. 7, pp. 1113-1122, 2010.
[12] O. Arrieta, R. M. Michel Ortega, G. Villanueva-Rodríguez et al., "Association of nutritional status and serum albumin levels with development of toxicity in patients with advanced non-small cell lung cancer treated with paclitaxel-cisplatin chemotherapy: a prospective study," BMC Cancer, vol. 10, article 50, 2010.

[13] L. M. Forrest, D. C. McMillan, C. S. McArdle, W. J. Angerson, and D. J. Dunlop, "Comparison of an inflammation-based prognostic score (GPS) with performance status (ECOG) in patients receiving platinum-based chemotherapy for inoperable non-small-cell lung cancer," British Journal of Cancer, vol. 90, no. 9, pp. 1704-1706, 2004.

[14] L. M. Forrest, D. C. McMillan, C. S. McArdle, W. J. Angerson, K. Dagg, and H. R. Scott, "A prospective longitudinal study of performance status, an inflammation-based score (GPS) and survival in patients with inoperable non-small-cell lung cancer," British Journal of Cancer, vol. 92, no. 10, pp. 1834-1836, 2005.

[15] D. J. F. Brown, R. Milroy, T. Preston, and D. C. McMillan, “The relationship between an inflammation-based prognostic score (Glasgow Prognostic Score) and changes in serum biochemical variables in patients with advanced lung and gastrointestinal cancer," Journal of Clinical Pathology, vol. 60, no. 6, pp. 705-708, 2007.

[16] E. Y. L. Leung, H. R. Scott, and D. C. McMillan, "Clinical utility of the pretreatment glasgow prognostic score in patients with advanced inoperable non-small cell lung cancer," Journal of Thoracic Oncology, vol. 7, no. 4, pp. 655-662, 2012.

[17] D. C. McMillan, "The systemic inflammation-based Glasgow Prognostic Score: a decade of experience in patients with cancer," Cancer Treatment Reviews, vol. 39, no. 5, pp. 534-540, 2013.

[18] Scottish Intercollegiate Guidelines Network (SIGN), Management of Patients with Lung Cancer, 2005, http://www.sign.ac .uk/pdf/sign80.pdf.

[19] D. Grose, G. Devereux, L. Brown et al., "Variation in comorbidity and clinical management in patients newly diagnosed with lung cancer in four Scottish centers," Journal of Thoracic Oncology, vol. 6, no. 3, pp. 500-509, 2011.

[20] Office of the Chief Statistician and Scottish Executive, "Scottish Index of Multiple Deprivation 2006," Tech. Rep., http://www.scotland.gov.uk/Publications/2006/10/13142913/0.

[21] L. M. Forrest, D. C. McMillan, C. S. McArdle, W. J. Angerson, and D. J. Dunlop, "Evaluation of cumulative prognostic scores based on the systemic inflammatory response in patients with inoperable non-small-cell lung cancer," British Journal of Cancer, vol. 89, no. 6, pp. 1028-1030, 2003.

[22] D. C. McMillan, J. E. M. Crozier, K. Canna, W. J. Angerson, and C. S. McArdle, "Evaluation of an inflammation-based prognostic score (GPS) in patients undergoing resection for colon and rectal cancer," International Journal of Colorectal Disease, vol. 22, no. 8, pp. 881-886, 2007.

[23] A. B. C. Crumley, R. C. Stuart, M. McKernan, A. C. McDonald, and D. C. McMillan, "Comparison of an inflammation-based prognostic score (GPS) with performance status (ECOG-ps) in patients receiving palliative chemotherapy for gastroesophageal cancer," Journal of Gastroenterology and Hepatology, vol. 23, no. 8, pp. e325-e329, 2008.

[24] A. L. Rich, L. J. Tata, R. A. Stanley et al., "Lung cancer in England: information from the National Lung Cancer Audit (LUCADA)," Lung Cancer, vol. 72, no. 1, pp. 16-22, 2011.

[25] N. MacDonald, "Terminology in cancer cachexia: importance and status," Current Opinion in Clinical Nutrition and Metabolic Care, vol. 15, no. 3, pp. 220-225, 2012. 
[26] G. V. Scagliotti, P. Parikh, J. Von Pawel et al., "Phase III study comparing cisplatin plus gemcitabine with cisplatin plus pemetrexed in chemotherapy-naive patients with advancedstage non-small-cell lung cancer," Journal of Clinical Oncology, vol. 26, no. 21, pp. 3543-3551, 2008.

[27] T. W. Du Clos and C. Mold, "C-reactive protein: an activator of innate immunity and a modulator of adaptive immunity," Immunologic Research, vol. 30, no. 3, pp. 261-277, 2004.

[28] T. Nozoe, T. Matsumata, and K. Sugimachi, "Preoperative elevation of serum C-reactive protein is related to impaired immunity in patients with colorectal cancer," American Journal of Clinical Oncology, vol. 23, no. 3, pp. 263-266, 2000.

[29] L. M. Coussens and Z. Werb, "Inflammation and cancer," Nature, vol. 420, no. 6917, pp. 860-867, 2002.

[30] R. Abramovitch, M. Marikovsky, G. Meir, and M. Neeman, "Stimulation of tumour growth by wound-derived growth factors," British Journal of Cancer, vol. 79, no. 9-10, pp. 13921398, 1999.

[31] K. Canna, M. Hilmy, D. C. Mcmillan et al., "The relationship between tumour proliferative activity, the systemic inflammatory response and survival in patients undergoing curative resection for colorectal cancer," Colorectal Disease, vol. 10, no. 7, pp. 663-667, 2008.

[32] S. B. Edge, D. R. Bird, and C. C. Compton, AJCC Cancer Staging Manual, 7th edition, 2009.

[33] B. J. Laird, S. Kaasa, D. C. McMillan et al., "Prognostic factors in patients with advanced cancer: a comparison of clinicopathological factors and the development of an inflammation-based prognostic system," Clinical Cancer Research, vol. 19, pp. 54565464, 2013. 


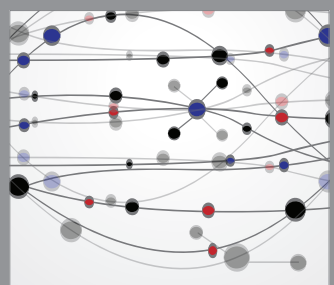

The Scientific World Journal
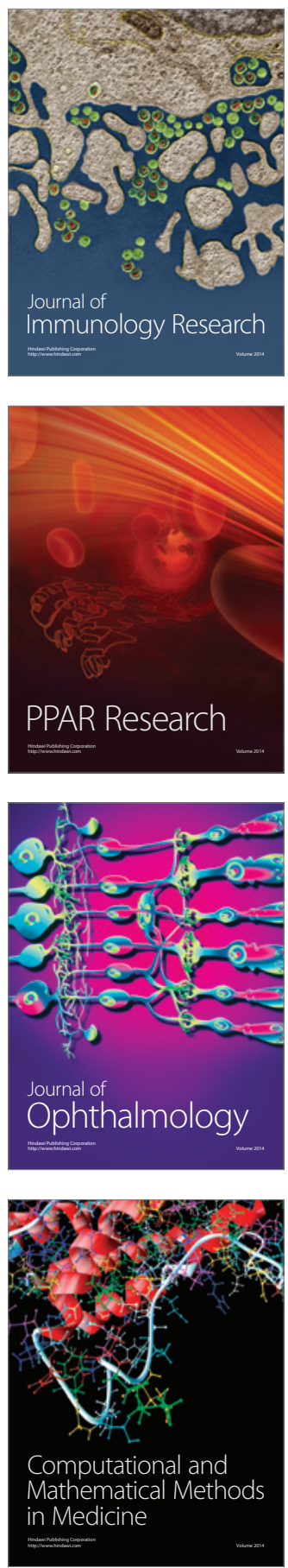

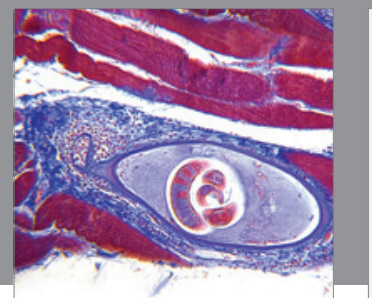

Gastroenterology

Research and Practice
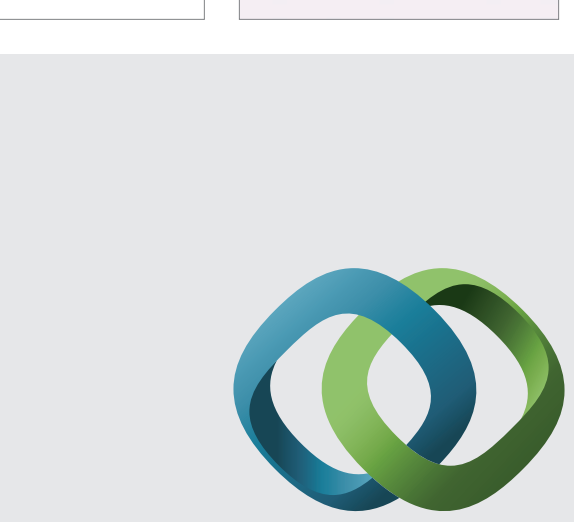

\section{Hindawi}

Submit your manuscripts at

http://www.hindawi.com
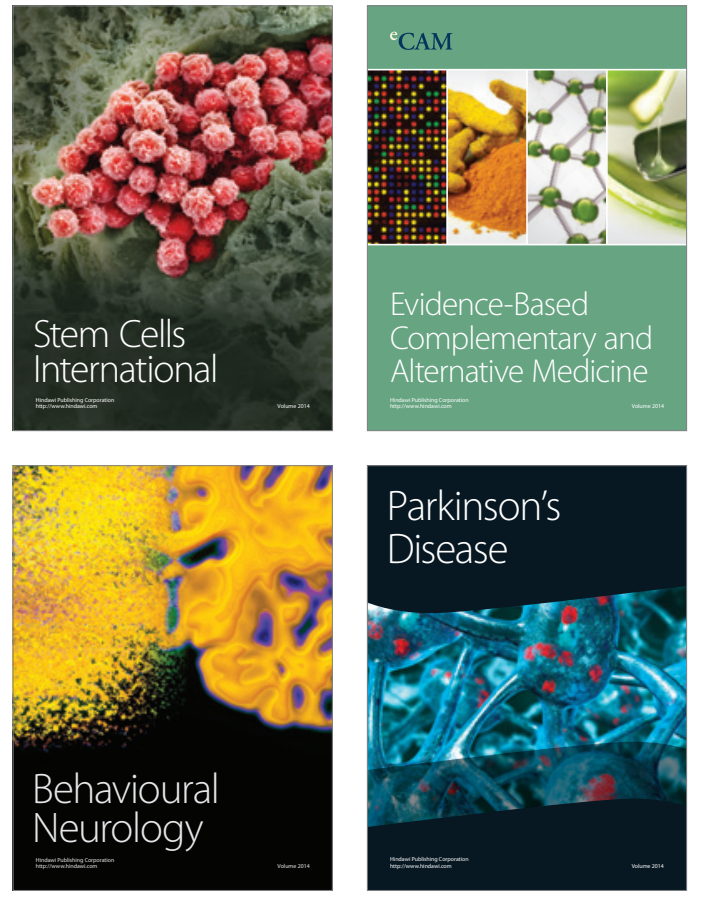
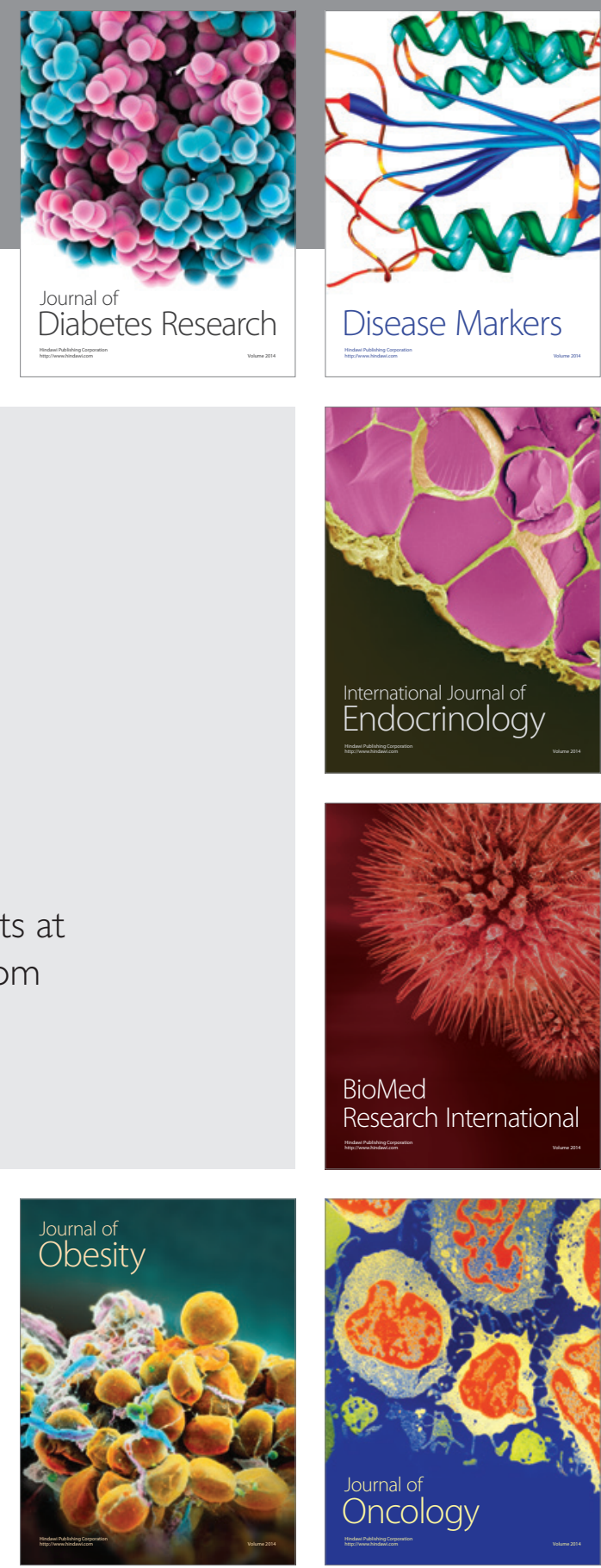

Disease Markers
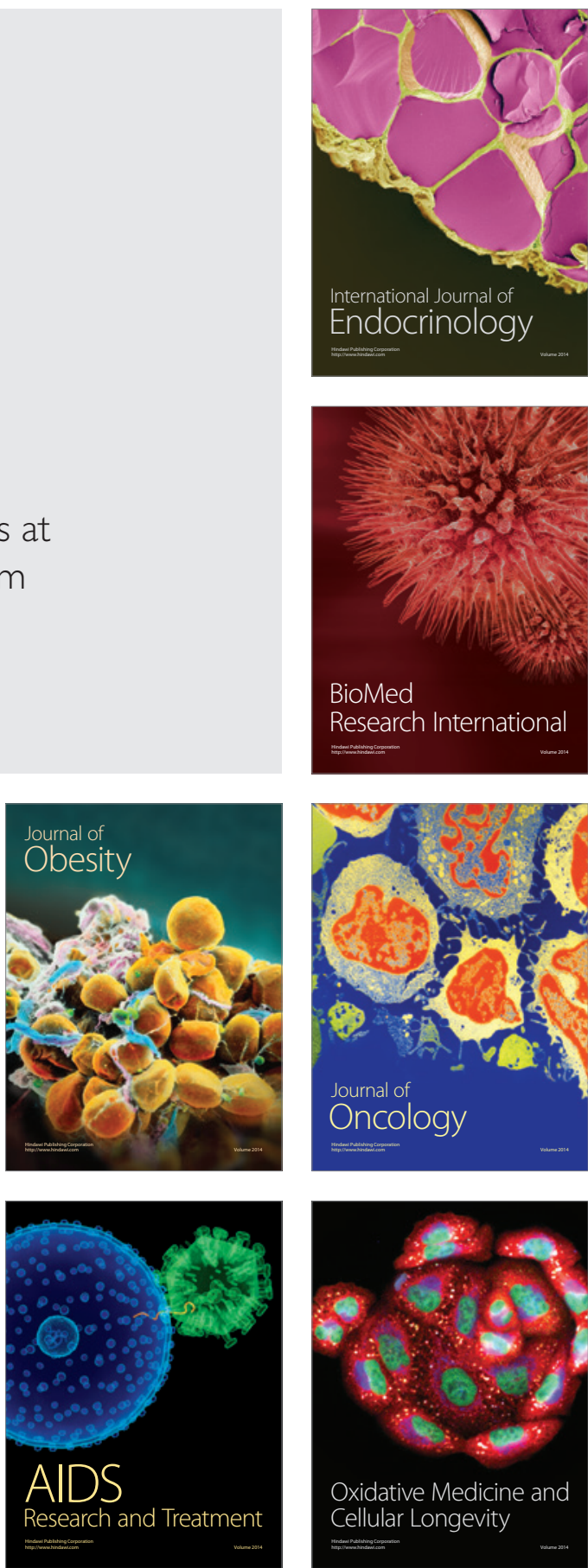